\title{
Clinical utility of FDG-PET in amyotrophic lateral sclerosis and Huntington's disease
}

*Federica Agosta, MD, PhD; Daniele Altomare, MS; Cristina Festari, MS; Stefania Orini, MD;

Federica Gandolfo, MD; *Marina Boccardi, PhD; Javier Arbizu, MD; Femke Bouwman, MD, PhD;

Alexander Drzezga, MD; Peter Nestor, MD; Flavio Nobili, MD; Zuzana Walker, MD; Marco

Pagani, PhD, for the EANM-EAN Task Force for the Prescription of FDG-PET for Dementing

Neurodegenerative Disorders.

\section{AFFILIATIONS}

Federica Agosta: Neuroimaging Research Unit, Institute of Experimental Neurology, Division of Neuroscience, San Raffaele Scientific Institute, Vita-Salute San Raffaele University, Milan, Italy. Daniele Altomare: LANE - Laboratory of Alzheimer's Neuroimaging \& Epidemiology, IRCCS S. Giovanni di Dio, Fatebenefratelli, Brescia, Italy; Department of Molecular and Translational Medicine, University of Brescia, Brescia, Italy.

Cristina Festari: LANE - Laboratory of Alzheimer's Neuroimaging \& Epidemiology, IRCCS S.

Giovanni di Dio, Fatebenefratelli, Brescia, Italy; Department of Molecular and Translational Medicine, University of Brescia, Brescia, Italy.

Stefania Orini: Alzheimer Operative Unit, IRCCS S. Giovanni di Dio, Fatebenefratelli, Brescia, Italy.

Federica Gandolfo: Alzheimer Operative Unit, IRCCS S. Giovanni di Dio, Fatebenefratelli, Brescia, Italy.

Marina Boccardi: LANVIE (Laboratoire de Neuroimagerie du Vieillissement), Dept of Psychiatry, University of Geneva, Geneva, Switzerland; LANE - Laboratory of Alzheimer's Neuroimaging \& Epidemiology, IRCCS S. Giovanni di Dio, Fatebenefratelli, Brescia, Italy. Javier Arbizu: Department of Nuclear Medicine. Clinica Universidad de Navarra. University of Navarra. Pamplona, Spain. 
Femke Bouwman: Department of Neurology \& Alzheimer Center, Amsterdam Neuroscience, VU University Medical Center, Amsterdam, the Netherlands.

Alexander Drzezga: Department of Nuclear Medicine, University Hospital of Cologne, University of Cologne and German Center for Neurodegenerative Diseases (DZNE), Germany. Peter Nestor: German Center for Neurodegenerative Diseases (DZNE), Magdeburg, Germany; Queensland Brain Institute, University of Queensland and at the Mater Hospital Brisbane.

Flavio Nobili: Department of Neuroscience (DINOGMI) University of Genoa and Polyclinic San Martino Hospital, Genoa, Italy.

Zuzana Walker: University College London, Division of Psychiatry \& Essex Partnership University NHS Foundation Trust, UK.

Marco Pagani: Institute of Cognitive Sciences and Technologies, CNR, Rome, Italy; Department of Nuclear Medicine, Karolinska Hospital Stockholm, Stockholm, Sweden.

\section{*Correspondents:}

Federica Agosta

Neuroimaging Research Unit, Institute of Experimental Neurology, Division of Neuroscience

San Raffaele Scientific Institute, Vita-Salute San Raffaele University, Milan, Italy

e-mail: agosta.federica@hsr.it

Tel.: 00390226433063

Fax.: 00390226433031

Marina Boccardi

LANVIE (Laboratoire du Neuroimagerie du Vieillissement), Dept of Psychiatry

University of Geneva, Geneva, Switzerland

e-mail: marina.boccardi@unige.ch

Tel.: 0041.(0)22.3055764

Fax.: 0041.(0)22.3054719 


\begin{abstract}
\end{abstract}
Aim: To evaluate the incremental value of FDG-PET over clinical tests in: (i) diagnosis of amyotrophic lateral sclerosis (ALS); (ii) picking early signs of neurodegeneration in patients with a genetic risk of Huntington's disease (HD); and detecting metabolic changes related to cognitive impairment in (iii) ALS and (iv) HD patients.

Methods: Four comprehensive literature searches were conducted using the PICO model to extract evidence from relevant studies. An expert panel then voted using the Delphi method on these four diagnostic scenarios.

Results: The availability of evidence was good for FDG-PET utility to support the diagnosis of ALS, poor for identifying presymptomatic subjects carrying HD mutation who will convert to HD, and lacking for identifying cognitive-related metabolic changes in both ALS and HD. After the Delphi consensual procedure, the panel did not support the clinical use of FDG-PET for any of the four scenarios.

Conclusion: Relative to other neurodegenerative diseases, the clinical use of FDG-PET in ALS and HD is still in its infancy. Once validated by disease-control studies, FDG-PET might represent a potentially useful biomarker for ALS diagnosis. FDG-PET is presently not justified as a routine investigation to predict conversion to $\mathrm{HD}$, nor to detect evidence of brain dysfunction justifying cognitive decline in ALS and HD.

Keywords: FDG-PET; Amyotrophic lateral sclerosis; Huntington's disease; Cognitive impairment Behavioural abnormalities; Mutation gene carrier. 


\section{BACKGROUND}

The lack of clinical guidelines for the use of FDG-PET in the diagnosis of dementia and other neurodegenerative diseases has led the European Association of Nuclear Medicine (EANM) and the European Academy of Neurology (EAN) to launch a joint initiative to guide clinicians in the use of the exam. The initiative included a set of 21 clinical questions, to be addressed based on literature evidence and expert consensus [1].

In this paper, we report the evidence assessment performed to evaluate the incremental value of FDG-PET over clinical tests in: (i) diagnosing amyotrophic lateral sclerosis (ALS); (ii) picking early signs of neurodegeneration in patients with a genetic risk of Huntington's disease (HD); and detecting metabolic changes related to cognitive impairment in patients with (iii) ALS and (iv) HD. Four literature searches were performed to assess the quality of evidence supporting the accuracy of FDG-PET in the above-mentioned conditions.

\section{METHODS}

Seven panelists, four from EANM and three from EAN, were appointed to produce recommendations taking into account the incremental value of FDG-PET, as added on clinical examination, for the evaluation of ALS and HD. Consensus recommendations were provided through a Delphi procedure, where panelists were encouraged to vote based on the available evidence and their expertise [2].

The methods for the project are described in detail elsewhere in this issue [2]. Briefly, we performed literature searches using harmonized PICO (Population, Intervention, Comparison, Outcome) question keywords edited by the experts, screened the studies for eligibility, extracted the data to assess their methodology quality, and provided an evidence assessment consistent with the EFNS guidance [3], and specific to the aim of assessing FDG-PET accuracy studies [2].

\subsection{PICO question(s) for this paper}


For this review, the PICO questions were whether FDG-PET should be performed, as adding diagnostic value (in terms of increased accuracy, and versus clinical confirmation) as compared to standard clinical assessment alone, to:

- confirm a clinical suspicion of ALS in patients with or without cognitive impairment (PICO 17);

- detect brain dysfunction related to cognitive deterioration in patients with ALS (PICO 18);

- $\quad$ pick early signs of neurodegeneration in patients with a genetic risk of HD (PICO 19);

- discriminate frontal-lobe hypometabolism responsible for cognitive deterioration in patients with HD (PICO 20).

\subsection{Eligibility criteria}

Only original full papers published in English on international impacted journals were considered, excluding reviews, management guidelines, abstracts and gray literature. Minimum sample sizes were set a priori at 10 for PICOs 17 and 19, 5 for PICO 18, and 20 for PICO 20.

\subsection{Literature search}

Electronic search strategy, developed and tested with panelists, was performed through predefined keywords strings, grounding on the specific PICO question and including a selection of terms taken from a largely inclusive literature selection, in order to pick all variants for the same keyword. The strings were made up of a common part for FDG-PET and of a PICO-specific part [2].

Literature searches were performed using the Medline and Embase databases, and included papers published online until November 2015. First, an independent screening of all included papers was performed by a neurologist or by a nuclear medicine physician with expertise in neurodegenerative disorders, who could include additional papers based on personal knowledge or tracking from references of papers. Then, the full texts of these potentially eligible studies were independently assessed for eligibility by the methodology group [2]. 


\subsection{Data extraction and quality assessment}

We extracted data to evaluate study features, population of interest, index test, gold/reference standard, critical/proxy outcomes, FDG-PET image assessment (visual or semi-quantitative methods), risk of bias, index test imprecision, applicability, effect size, and effect inconsistency [2]. Data extractor for this review was DA. Critical outcomes were validated measures of test performance (accuracy, sensitivity, specificity, AUC, positive and negative predictive values and likelihood ratios). An additional proxy outcome was admitted for PICO 19, consisting of a significant FDG-PET hypometabolic pattern associated to presymptomatic HD gene carriers who subsequently develop HD, using clinical conversion at follow-up as the reference standard.

Evidence was assessed relative to individual studies (https://drive.google.com/open?id=0B0_JB3wzTvbpVFYtUGxHdGZWYmc) and by outcome. A final assessment was formulated, summarizing the relative availability of evidence, i.e. ranking the quality and availability of evidence of this PICO among all of the 21 PICOs of the project. This ranking was summarized as very poor/lacking, poor, fair or good.

\section{RESULTS}

For the four PICOs included in this review, 290 papers were identified by the referent panelist (FA). Fifty-three studies reported the comparison of interest and were examined by the methodology group. Of these, only four did contain the critical outcomes, properly quantifying FDG-PET diagnostic utility (Figure 1). The evidence assessment denoted a good evidence of FDGPET utility to support the diagnosis of ALS and a poor evidence in picking neurodegeneration in presymptomatic subjects carrying HD mutation. Semi-quantitative evidence was lacking for assessing FDG-PET utility to identify ALS-related brain dysfunction justifying cognitive impairment in ALS patients, and frontal-lobe hypometabolism responsible for cognitive decline in 
patients with HD. After the Delphi consensual procedure, the panel did not support the clinical use of FDG-PET for any of the four aims (Table 1, [1]).

\subsection{PICO 17: Use of FDG-PET to confirm clinical diagnosis of ALS}

Among the 74 papers identified and screened, 16 were sent to the methodology group for data extraction and assessment (see Figure 1 - PICO 17). Eight papers were excluded for the following reasons: four papers [4-7] did not have the minimum sample size; two studies used a different index test (Oxygen-15 PET) [8, 9]; Chiò et al., (2010) [10] is a case report study; and Carluer at al., (2015) [11] aimed to investigate the neural substrate of theory of mind deficits in ALS patients. Among the remaining eight papers, critical outcomes on FDG-PET diagnostic utility in ALS were available in two $[12,13]$ (see Table 2 - PICO 17; data extraction table available at https://drive.google.com/file/d/0B0_JB3wzTvbpWDhwaF8zSGdCd3c/view?usp=sharing). The two papers $[12,13]$, including a total of 265 ALS patients and 60 healthy controls, showed that the metabolism of specific regions of interest distinguished ALS patients from healthy controls with high sensitivity (95.4 and 94.8\%, respectively), specificity (82.5 and 80\%, respectively), and accuracy (93.2 and 91.8\%, respectively). The remaining six studies provided only evidence of hypometabolism in ALS patients relative to controls without diagnostic outcomes [14-19]. The most common metabolic pattern in ALS patients compared to healthy controls consisted of hypometabolism in the frontal (primarily in motor, premotor and prefrontal cortex) and occipital lobes. Relative hypermetabolism was consistently observed in the brainstem (midbrain and pons), medial temporal lobe (including hippocampus), cerebellum and amygdalae.

The relative availability of evidence, as ranked among the 21 PICOs of the whole project, supporting diagnostic utility of FDG-PET in distinguishing patients with ALS from healthy people was ranked as good. However, the consensual recommendation for PICO 17 was defined on Delphi round II, with six panelists not supporting clinical utility of FDG PET in the diagnosis of ALS, based on the greater utility of other instruments and the limited number of studies. 


\subsection{PICO 18: Use of FDG-PET to detect cognitive-related brain dysfunction in ALS}

Thirty-one papers were identified and screened, but only five were qualified for further analysis and sent to the methodology team for evidence assessment (see Figure 1 - PICO 2). Of these, one paper was excluded because not pertinent [20]. The data extraction table is available at https://drive.google.com/file/d/OB0_JB3wzTvbpUXBqWGZfd0VQVkk/view?usp=sharing.

Diagnostic outcomes were not available in any of the examined papers, denoting lack of objective evidence in supporting the incremental diagnostic value of FDG-PET in identifying ALS patients with cognitive impairment as compared to clinical/neuropsychological assessment. Papers were anyway assessed considering the available results, in order to provide potentially useful information to panelists' decisions. All the four studies reported findings on the relation between hypometabolic patterns and cognitive dysfunction in ALS. Hypometabolism was frequently observed in the frontal cortex, consistent with a clinical picture of FTD [11, 21, 22], especially in its behavioral variant [21]. Hypometabolism in such patients was related to impairment in word fluency [18, 21], psychomotor speed, and sustained attention [21]. Finally, a study showed a correlation between frontal hypometabolism and theory of mind deficits in ALS patients [11].

Being these findings based on correlation data rather than on evidence of test performance, the availability of formal evidence of FDG-PET clinical utility in detecting cognition-related brain dysfunction in ALS patients was considered to be lacking. No agreement was reached through the Delphi procedure for this PICO. The panel concluded that FDG-PET may have diagnostic and prognostic value in selected cases, but no recommendation can be formulated based on either data nor on the consensus procedure.

\subsection{PICO 19: FDG-PET to predict HD in presymptomatic subjects carrying HD gene} mutation 
Among the 144 papers identified, 26 were eligible for further assessment and sent to the methodology team (see Figure 1 - PICO 19). Eighteen papers were excluded for the following reasons: in two studies PET scans were obtained using radiotracers other than FDG [23, 24]; two studies did not reach the recommended minimum sample size [25, 26]; seven papers did not include the target population (i.e., subjects were not "at genetic risk for HD", but they were already HD patients) [27-33]; in six papers, subjects were considered at risk based on positive family history but a genetic test was not performed [34-39]; and in one study, FDG-PET results were not reported although the scans were obtained [40]. Eight papers included the comparison of interest. The data extraction table is available at https://drive.google.com/file/d/0B0_JB3wzTvbpRkVja29fMTdRVTg/view?usp=sharing.

Critical outcomes were available in only one paper (see Table 3 - PICO 19) [41], which showed that striatal FDG-PET uptake was able to identify presymptomatic HD subjects who will convert to manifest HD with an area under the ROC curve of 0.94 for caudate and 0.80 for putamen. Clinical conversion at follow-up was used as the reference standard [41]. Hypometabolism in the striatum (i.e., caudate and putamen) in presymptomatic mutation carriers who subsequently develop HD as compared to non-converters was found in three additional studies [42-44] but diagnostic values were not reported.

Other studies provided only evidence of striatal hypometabolism associated to presymptomatic HD gene carriers as compared to healthy controls [45-48]. Although such metabolic patterns cannot be uniquely attributed to HD-related neurodegeneration since no information about the subjects' conversion into HD was provided, it is interesting to note that it is consistent with the patterns observed relative to non-converters [41].

Relative to the evidence available for the other PICOs, the availability of formal evidence supporting clinical utility of FDG-PET in identifying subjects with a genetic risk of HD was ranked as poor. The consensual recommendation for PICO 19 was defined on Delphi round II, with six 
panelists recommending not to support FDG-PET use in clinical settings and limiting it to research purposes.

\subsection{PICO 20: FDG-PET to detect frontal-lobe hypometabolism responsible for cognitive deterioration in patients with HD}

Among the 41 papers identified and screened, six were provided to the methodology team for data extraction and assessment (see Figure 1 - PICO 7). Two papers were excluded as one study included presymptomatic HD mutation carriers [43], while in the second one patients did not undergo neuropsychological assessment, with consequent lack of an objective confirmation of "cognitive deterioration" [31].

Critical outcomes on FDG-PET diagnostic utility in picking frontal-lobe hypometabolism in HD patients were available in only one of the four examined papers [49] (see Table 4 - PICO 20; data extraction table available at https://drive.google.com/file/d/0B0_JB3wzTvbpWlF4a2RQMU9WWVU/view?usp=sharing). This study showed hypometabolism in eight HD patients compared to healthy controls, in prefrontal and premotor regions [49]. Moreover, a significant correlation was found between frontal lobe hypometabolism and cognitive performance, as measured by means of a series of script generation and script sorting tasks [49] (see last line in Table 4 - PICO 20).

The remaining three papers did not provide critical outcomes. One study did not assess frontal cortical metabolism, being the analyses limited to caudate, putamen and thalamus [50]. Kuwert et al., 1990 [29] found that cerebellar metabolism correlated with the degree of dementia (which was determined using a score derived from a psychometric test battery), but correlations between frontal metabolism and neuropsychological tests were not reported. In a third study [37], frontal, temporal and parietal metabolism was lower in HD cases with dementia as compared with those without dementia and controls, but correlation with cognitive performance was not examined in greater detail. 
The availability of evidence was considered as lacking. Agreement was achieved on Delphi round III, with five panelists not supporting clinical use of FDG-PET in detecting frontal-lobe hypometabolism responsible for cognitive decline in patients with HD.

\section{DISCUSSION}

In this paper, we assessed the evidence in supporting the clinical utility of FDG-PET in ALS and HD patients, in the context of 21 scenarios related to the use of FDG-PET in the diagnosis of neurodegenerative disorders [1].

ALS diagnosis is based on clinical history, neurologic examination and symptom progression, and is supported by neurophysiological testing. Several FDG-PET studies in small samples of FTD patients with motor neuron disease and further investigations in larger ALS cohorts have shown significant differences of metabolism relative to healthy controls [4-7, 14-19]. Hypometabolism in the primary motor and premotor cortices but also in the frontal and parietal lobes was observed. Relative hypermetabolism was also found in the mediotemporal cortex, cerebellum, and brainstem. Up to November 2015, two studies $[12,13]$ evaluated the value of FDGPET in large prospective cohorts of patients with ALS around the time of diagnosis. Overall, the diagnostic value of FDG-PET versus a control population showed high accuracy. However, the specific search of metabolic abnormalities for the purpose of making a firm diagnosis of ALS was not recommended by the panelists. The uniformly proposed reasons (during the Delphi panel procedure) for not supporting the use of FDG-PET in the clinical diagnosis of ALS mainly relied on the availability of other routine exams that are more directly informative for this disease (i.e., clinical signs of motor impairment and neurophysiological testing). Importantly, the panelists also recognized that the implementation of FDG-PET in the standard diagnostic work-up would need validation of its specificity to discriminate ALS patients from subjects with disease mimics. Finally, the clinical value of FDG-PET in ALS patients would be enhanced by studies investigating its sensitivity in detecting upper motor neuron involvement before clinical symptoms become apparent 
(i.e., in patients with the lower motor neuron variant of the disease). Of note, two large FDG-PET studies in ALS [51, 52] have been published after November 2015 including 259 and 175 patients, respectively. Although they were not included in the evidence originally assessed and used to achieve the consensus recommendations, it is worth noting that the overall accuracy in discriminating ALS patients from healthy controls was above 99\% [51, 52]. While recognizing the additional evidence provided by these recent studies [51, 52], we also believe that the panel's conclusions would not have changed as the accuracy of FDG-PET was not tested against clinical and neurophysiological tests nor in separating ALS patients from ALS-mimicking disorders.

Cognitive impairment and behavioural symptoms affect approximately $50 \%$ of people with ALS, of whom 15\% develop FTD [53]. Research has indicated that cognitive and behavioural deficits are associated with reduced survival, disengagement with life prolonging interventions, and increased caregiver burden [54]. Thus, clinical utility in detecting brain dysfunction related to cognitive and behavioural deterioration in patients with ALS has long been recognized. Advances in MRI have enabled mapping of functional and structural abnormalities extending beyond the motor system [54]. Evidence is increasing that FDG-PET shows hypometabolism in ALS patients with cognitive and/or behavioural abnormalities $[11,21,22,18]$. Panelists recognized that functional neuroimaging with FDG-PET, additionally or alternatively to structural MRI, is required by the current diagnostic criteria for probable FTD at the dementia stage [55]. On the other hand, the clinical utility of FDG-PET in ALS patients with cognitive and/or behavioural changes not fulfilling clinical criteria for FTD diagnosis is more controversial. There is no objective evidence so far for an incremental diagnostic value of FDG-PET versus comprehensive cognitive and behavioural testing to allow attributing such deficits to ALS pathology. In agreement with the Strong consensus criteria [53], the panelists suggested that FDG-PET is adequate for research purposes or in selected cases to verify the expected pattern of abnormality while it is not yet recommended to be of general utility clinically. Larger longitudinal studies involving patients at 
disease onset are needed to evaluate whether FDG-PET can have a useful role in understanding the mechanisms underlying ALS-related cognitive or behavioural deficits along the disease course.

Relative to the other PICOs, our assessment denoted poor availability of evidence that FDGPET is clinically useful in picking neurodegeneration in patients at genetic risk of HD. Striatal hypometabolism may be an earlier finding as compared to striatal volume loss on MRI [41-44]. Additionally, one study showed that decreases in putaminal and caudate metabolism identified presymptomatic subjects carrying HD gene mutation who developed manifest motor symptoms suggestive of HD after as many as 5 years from PET scan [41]. However, the paucity of studies in this field together with the present lack of effective neuroprotective drugs led the panelists to suggest that FDG-PET is not justified as a routine investigation to predict conversion to overt HD. As in the case of ALS, additional evidence on the value of FDG-PET in predicting conversion of presymptomatic HD into manifest HD was investigated by a study published after November 2015 [56]. Lopez-Mora et al found a significant striatal hypometabolism in $18 \mathrm{HD}$ patients relative to 15 presymptomatic gene-expanded carriers but the actual discriminative value was not reported [56]. Although striatal hypometabolism was also observed in the group of premanisfest HD subjects compared with healthy controls, regardless of the time to disease onset, individual standard uptake values overlapped between groups [56]. Finally, only one study explored the correlations between patterns of hypometabolism and cognitive performance in a very small sample of HD patients [49]. Based on the current knowledge, panelists agreed that FDG-PET would not add clinically useful information to detect frontal-lobe hypometabolism responsible for cognitive deterioration in known HD patients. The reason for the negative response by the majority of the panelists was based on the lack of data.

Relative to other neurodegenerative diseases [1], the use of FDG-PET in ALS and HD is still in its infancy. Therefore, an important limitation of this work was the paucity, or, in some circumstances, complete lack of evidence on which to base panelists' recommendations. Collection of more robust formal evidence is required to demonstrate the clinical value of FDG-PET in these 
two conditions. In addition, combining application of tracers, targeting different pathological processes like neuroinflammation and excitotoxicity, might provide novel insights to facilitate diagnosis in complex neurodegenerative diseases like ALS and HD. Finally, more widespread implementation of simultaneous hybrid PET-MRI scanners might aid in developing multiparametric markers for further characterization of the diseases. 


\section{Acknowledgements}

The procedure for assessing scientific evidence and defining consensual recommendations was funded by the European Association of Nuclear Medicine (EANM) and by the European Academy of Neurology (EAN). We thank the Guidelines working group of EAN, particularly Simona Arcuti and Maurizio Leone, for methodological advice. 
Table 1. Availability of evidence and panelists' decisions supporting the use of FDG-PET in ALS and HD.

\begin{tabular}{|l|l|l|l|}
\hline \multicolumn{1}{|c|}{ PICO } & $\begin{array}{c}\text { RELATIVE } \\
\text { AVAILABILITY } \\
\text { OF EVIDENCE }\end{array}$ & $\begin{array}{c}\text { PANELISTS } \\
\text { RECOMMENDATIONS }\end{array}$ & $\begin{array}{l}\text { MAIN REASONS FOR } \\
\text { FINAL DECISION }\end{array}$ \\
\hline $\begin{array}{l}\text { 17- ALS } \\
\text { diagnosis }\end{array}$ & Good & NO & $\begin{array}{l}\text { Other methods are more } \\
\text { useful. }\end{array}$ \\
\hline $\begin{array}{l}18-\text { ALS-related } \\
\text { decline }\end{array}$ & Lacking & NO & $\begin{array}{l}\text { Diagnostic and } \\
\text { prognostic value in } \\
\text { selected cases. }\end{array}$ \\
\hline $\begin{array}{l}19-\text { preclinical } \\
\text { HD }\end{array}$ & Poor & NO & $\begin{array}{l}\text { Only for research } \\
\text { purposes. }\end{array}$ \\
\hline $\begin{array}{l}20-\text { HD-related } \\
\text { decline }\end{array}$ & Lacking & $\begin{array}{l}\text { Only for research } \\
\text { purposes. }\end{array}$ \\
\hline
\end{tabular}


Table 2 - PICO 17. Table reports the quality of evidence for each critical outcome.

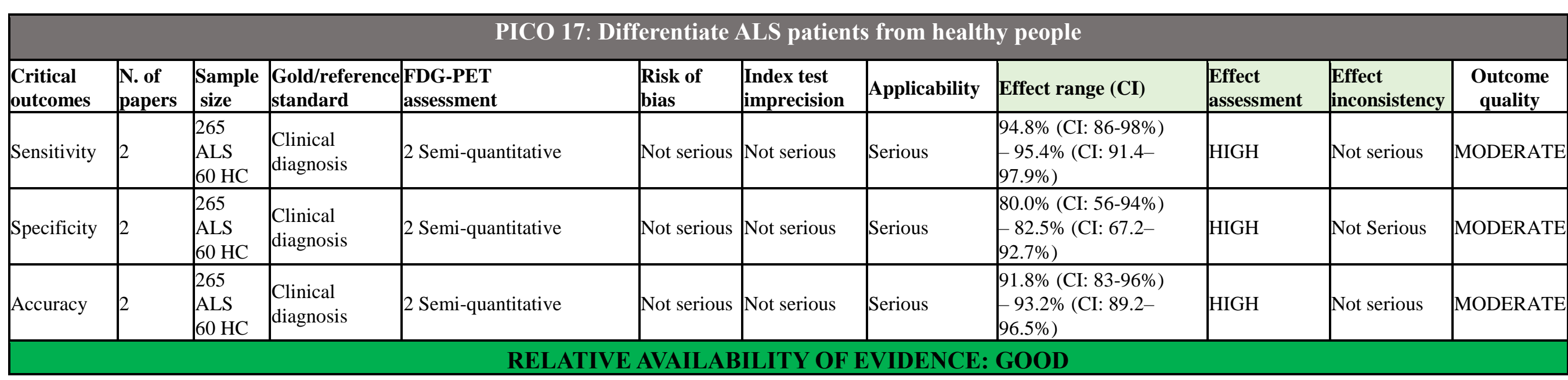

Risk of bias: assessment of the study design and other methodological features (e.g., patient selection, clinical diagnostic criteria used).

Index test methods: assessment of index test methodology (e.g., technical details, image analysis methods and statistical analysis).

Applicability: representativeness of the studied population and index test reproducibility in clinical practice (semi-quantitative methods correspond to 'serious' indirectness, visual + semi-quantitative methods correspond to 'not serious' indirectness, due to partial implementation of quantitation in clinical practice).

Effect: lowest and highest values for each critical outcome; when more values were obtained for the same outcome, the highest was reported.

Effect assessment: 51-70\% low, 71-80\% moderate, 81-100\% high.

Effect inconsistency: 'Not serious' if lowest and highest values difference was 0-20, 'serious' 21-40, 'very serious' $>40$.

Outcome quality: summary of evidence as from all columns. 
Table 3 - PICO 19. Table reports the quality of evidence for each critical outcome. Please see legend for Table PICO 17.

\begin{tabular}{|l|l|l|l|l|l|l|l|l|l|l|l|}
\hline \multicolumn{7}{|c|}{ PICO 19: Differentiate among pre-HID who will develop HD } \\
\hline $\begin{array}{l}\text { Critical } \\
\text { outcomes }\end{array}$ & $\begin{array}{l}\text { N. of } \\
\text { papers }\end{array}$ & Sample size & Gold/reference standard & $\begin{array}{l}\text { FDG-PET } \\
\text { assessment }\end{array}$ & $\begin{array}{l}\text { Risk of } \\
\text { bias }\end{array}$ & $\begin{array}{l}\text { Index test } \\
\text { imprecision }\end{array}$ & Applicability & Effect (CI) & $\begin{array}{l}\text { Effect } \\
\text { assessment }\end{array}$ & $\begin{array}{l}\text { Effect } \\
\text { inconsistency }\end{array}$ & $\begin{array}{l}\text { Outcome } \\
\text { quality }\end{array}$ \\
\hline AUC & 1 & $\begin{array}{l}26 \text { pre-HD } \\
\text { converter } \\
17 \text { pre-HD non- } \\
\text { converter }\end{array}$ & Conversion at follow-up & Semi-quantitative & Not serious & Not serious & Serious & $\begin{array}{l}94 \%(\mathrm{CI} \\
\text { NA) }\end{array}$ & HIGH & NA \\
\hline \multicolumn{7}{|c|}{ RELATIVE AVAILABILITY OF EVIDENCE: POOR } \\
\hline
\end{tabular}


Table 4 - PICO 20. Table reports the quality of evidence for each critical outcome. Please see legend for Table PICO 17.

\section{PICO 20: Frontal hypometabolism related/correlated to cognitive deterioration in HD patients}

\begin{tabular}{|c|c|c|c|c|c|c|c|c|c|c|c|c|}
\hline \multirow{2}{*}{$\begin{array}{l}\text { Critical } \\
\text { outcomes }\end{array}$} & \multirow{2}{*}{$\begin{array}{l}\text { N. of } \\
\text { papers }\end{array}$} & \multirow{2}{*}{$\begin{array}{l}\text { Sample } \\
\text { size }\end{array}$} & \multirow{2}{*}{$\begin{array}{l}\text { Gold/ } \\
\text { reference } \\
\text { standard }\end{array}$} & \multirow{2}{*}{$\begin{array}{l}\text { FDG-PET } \\
\text { assessment }\end{array}$} & \multirow[b]{2}{*}{ Risk of bias } & \multirow{2}{*}{$\mid \begin{array}{l}\text { Index test } \\
\text { imprecision }\end{array}$} & \multirow{2}{*}{$\begin{array}{l}\text { Applicabilit } \\
\text { y }\end{array}$} & \multicolumn{2}{|c|}{ Effect (statistically significant correlations) } & \multirow{2}{*}{$\begin{array}{l}\text { Effect } \\
\text { assessment }\end{array}$} & \multirow{2}{*}{$\begin{array}{l}\text { Effect } \\
\text { inconsistency }\end{array}$} & \multirow{2}{*}{$\begin{array}{l}\text { Outcome } \\
\text { quality }\end{array}$} \\
\hline & & & & & & & & \begin{tabular}{|l|}
$\begin{array}{l}\text { Frontal lobe } \\
\text { hypometabolism }\end{array}$ \\
\end{tabular} & Cognitive domain & & & \\
\hline \multirow{5}{*}{\begin{tabular}{|l|} 
Correlation \\
between \\
metabolism \\
in frontal lobe \\
regions and \\
cognitive \\
performances \\
(measured by \\
means of a \\
series of \\
script \\
generation \\
and script \\
sorting tasks) \\
\end{tabular}} & & \multirow{5}{*}{$8 \mathrm{HD}$} & \multirow{5}{*}{$\begin{array}{l}\text { Genetic/ } \\
\text { clinical } \\
\text { diagnosis }\end{array}$} & \multirow{5}{*}{$\begin{array}{l}\text { Semi- } \\
\text { quantitative }\end{array}$} & \multirow{5}{*}{ Not serious } & \multirow{5}{*}{ Not serious } & \multirow{5}{*}{ Serious } & $\begin{array}{l}\text { Inferior frontal gyrus } \\
\text { bilaterally, left precentral } \\
\text { gyrus }\end{array}$ & $\begin{array}{l}\text { Sequencing errors } \\
\text { (script generation) }\end{array}$ & \multirow{5}{*}{ HIGH } & \multirow{5}{*}{ NA } & \multirow{5}{*}{ HIGH } \\
\hline & & & & & & & & $\begin{array}{l}\text { Middle frontal gyrus } \\
\text { bilaterally, right superior } \\
\text { frontal gyrus, left precentral } \\
\text { gyrus }\end{array}$ & $\begin{array}{l}\text { Boundary errors } \\
\text { (script generation) }\end{array}$ & & & \\
\hline & & & & & & & & $\begin{array}{l}\text { Right superior frontal gyrus, } \\
\text { left inferior frontal gyrus }\end{array}$ & $\begin{array}{l}\text { Perseverative } \\
\text { errors (script } \\
\text { generation) } \\
\end{array}$ & & & \\
\hline & & & & & & & & $\begin{array}{l}\text { Left superior frontal gyrus, left } \\
\text { middle frontal gyrus }\end{array}$ & $\begin{array}{l}\text { Relevant intrusion } \\
\text { (script generation) }\end{array}$ & & & \\
\hline & & & & & & & & $\begin{array}{l}\text { Left middle frontal gyrus, right } \\
\text { inferior frontal gyrus }\end{array}$ & $\begin{array}{l}\text { Sequencing errors } \\
\text { (script sorting) }\end{array}$ & & & \\
\hline
\end{tabular}

Sequencing errors (a displacement in the logical sequence of actions within a script) were used to evaluate the temporal aspect of the script. Boundary errors (when the generation of events stops short of the stated endpoint or extends beyond this point) were used to evaluate the temporal dimension of the script. Perseverative errors consist of actions that are repeated more than once in a script 
Figure legends

Figure 1. PRISMA flowchart of selected papers for PICOs 17-20 (adapted from [57]).

Figure 2. Metabolic patterns in ALS and HD with cognitive deficits. A) Axial FDG-PET image of a 35 year old woman with ALS and a dysexecutive syndrome, showing a frank frontal hypometabolsim. B) Axial FDG-PET image of a 56 year old man with a psychiatric presentation of HD and minimal motor signs. There is a profound reduced uptake of both basal ganglia and moderately reduced uptake in the right thalamus.

Patient A: courtesy of Irina Savitcheva, Medical Radiation Physics and Nuclear Medicine Imaging IRA, Karolinska University Hospital Huddinge, Sweden; patient B: courtesy of Flavio Nobili, Department of Neuroscience (DINOGMI) University of Genoa and Polyclinic San Martino Hospital, Genoa, Italy. 


\section{References}

1. Nobili F, Arbizu J, Bouwman FH, Drzezga A, Agosta F, Nestor P et al. EANM-EAN recommendations for the use of brain 18F-Fluorodeoxyglucose Positron Emission Tomography (FDG-PET) in neurodegenerative cognitive impairment and dementia: Delphi consensus. Eur J Neurol. 2018; being submitted.

2. Boccardi M, Festari C, Altomare D, Gandolfo F, Orini S, Nobili F et al. Assessing accuracy of diagnostic FDG-PET studies to define clinical use for diagnosis of neurodegenerative disorders. Eur J Nucl Med Mol Imaging. 2018; In this Issue.

3. Leone MA, Brainin M, Boon P, Pugliatti M, Keindl M, Bassetti CL. Guidance for the preparation of neurological management guidelines by EFNS scientific task forces - revised recommendations 2012. Eur J Neurol. 2013;20(3):410-9. doi:10.1111/ene.12043.

4. Coon EA, Whitwell JL, Parisi JE, Dickson DW, Josephs KA. Right temporal variant frontotemporal dementia with motor neuron disease. J Clin Neurosci. 2012;19(1):85-91. doi:10.1016/j.jocn.2011.06.007.

5. Garraux G, Salmon E, Degueldre C, Lemaire C, Franck G. Medial temporal lobe metabolic impairment in dementia associated with motor neuron disease. J Neurol Sci. 1999;168(2):145-50. 6. Hoffman JM, Mazziotta JC, Hawk TC, Sumida R. Cerebral glucose utilization in motor neuron disease. Arch Neurol. 1992;49(8):849-54.

7. Jeong Y, Park KC, Cho SS, Kim EJ, Kang SJ, Kim SE et al. Pattern of glucose hypometabolism in frontotemporal dementia with motor neuron disease. Neurology. 2005;64(4):734-6. doi:10.1212/01.WNL.0000152047.58767.9D.

8. Tanaka M, Kondo S, Hirai S, Sun X, Yamagishi T, Okamoto K. Cerebral blood flow and oxygen metabolism in progressive dementia associated with amyotrophic lateral sclerosis. J Neurol Sci. 1993;120(1):22-8.

9. Tanaka M, Ichiba T, Kondo S, Hirai S, Okamoto K. Cerebral blood flow and oxygen metabolism in patients with progressive dementia and amyotrophic lateral sclerosis. Neurol Res. 2003;25(4):351-6. doi:10.1179/016164103101201670.

10. Chio A, Calvo A, Moglia C, Restagno G, Ossola I, Brunetti M et al. Amyotrophic lateral sclerosis-frontotemporal lobar dementia in 3 families with p.Ala382Thr TARDBP mutations. Arch Neurol. 2010;67(8):1002-9. doi:10.1001/archneurol.2010.173.

11. Carluer L, Mondou A, Buhour MS, Laisney M, Pelerin A, Eustache F et al. Neural substrate of cognitive theory of mind impairment in amyotrophic lateral sclerosis. Cortex. 2015;65:19-30. doi:10.1016/j.cortex.2014.12.010. 
12. Pagani M, Chio A, Valentini MC, Oberg J, Nobili F, Calvo A et al. Functional pattern of brain FDG-PET in amyotrophic lateral sclerosis. Neurology. 2014;83(12):1067-74.

doi:10.1212/WNL.0000000000000792.

13. Van Laere K, Vanhee A, Verschueren J, De Coster L, Driesen A, Dupont P et al. Value of 18fluorodeoxyglucose-positron-emission tomography in amyotrophic lateral sclerosis: a prospective study. JAMA Neurol. 2014;71(5):553-61. doi:10.1001/jamaneurol.2014.62.

14. Cistaro A, Pagani M, Montuschi A, Calvo A, Moglia C, Canosa A et al. The metabolic signature of C9ORF72-related ALS: FDG PET comparison with nonmutated patients. Eur J Nucl Med Mol Imaging. 2014;41(5):844-52. doi:10.1007/s00259-013-2667-5.

15. Cistaro A, Valentini MC, Chio A, Nobili F, Calvo A, Moglia C et al. Brain hypermetabolism in amyotrophic lateral sclerosis: a FDG PET study in ALS of spinal and bulbar onset. Eur J Nucl Med Mol Imaging. 2012;39(2):251-9. doi:10.1007/s00259-011-1979-6.

16. Dalakas MC, Hatazawa J, Brooks RA, Di Chiro G. Lowered cerebral glucose utilization in amyotrophic lateral sclerosis. Ann Neurol. 1987;22(5):580-6. doi:10.1002/ana.410220504.

17. Hatazawa J, Brooks RA, Dalakas MC, Mansi L, Di Chiro G. Cortical motor-sensory hypometabolism in amyotrophic lateral sclerosis: a PET study. J Comput Assist Tomogr. 1988;12(4):630-6.

18. Ludolph AC, Langen KJ, Regard M, Herzog H, Kemper B, Kuwert T et al. Frontal lobe function in amyotrophic lateral sclerosis: a neuropsychologic and positron emission tomography study. Acta Neurol Scand. 1992;85(2):81-9.

19. Rajagopalan V, Pioro EP. Comparing brain structural MRI and metabolic FDG-PET changes in patients with ALS-FTD: 'the chicken or the egg?' question. J Neurol Neurosurg Psychiatry. 2015;86(9):952-8. doi:10.1136/jnnp-2014-308239.

20. Solje E, Aaltokallio H, Koivumaa-Honkanen H, Suhonen NM, Moilanen V, Kiviharju A et al. The Phenotype of the C9ORF72 Expansion Carriers According to Revised Criteria for bvFTD. PLoS One. 2015;10(7):e0131817. doi:10.1371/journal.pone.0131817.

21. Boeve BF, Boylan KB, Graff-Radford NR, DeJesus-Hernandez M, Knopman DS, Pedraza O et al. Characterization of frontotemporal dementia and/or amyotrophic lateral sclerosis associated with the GGGGCC repeat expansion in C9ORF72. Brain. 2012;135(Pt 3):765-83. doi:10.1093/brain/aws004.

22. Canosa A, Pagani M, Cistaro A, Montuschi A, Iazzolino B, Fania P et al. 18F-FDG-PET correlates of cognitive impairment in ALS. Neurology. 2016;86(1):44-9. doi:10.1212/WNL.0000000000002242. 
23. Matusch A, Saft C, Elmenhorst D, Kraus PH, Gold R, Hartung HP et al. Cross sectional PET study of cerebral adenosine A(1) receptors in premanifest and manifest Huntington's disease. Eur J Nucl Med Mol Imaging. 2014;41(6):1210-20. doi:10.1007/s00259-014-2724-8.

24. Politis M, Pavese N, Tai YF, Tabrizi SJ, Barker RA, Piccini P. Hypothalamic involvement in Huntington's disease: an in vivo PET study. Brain. 2008;131(Pt 11):2860-9. doi:10.1093/brain/awn244.

25. Grafton ST, Mazziotta JC, Pahl JJ, St George-Hyslop P, Haines JL, Gusella J et al. A comparison of neurological, metabolic, structural, and genetic evaluations in persons at risk for Huntington's disease. Ann Neurol. 1990;28(5):614-21. doi:10.1002/ana.410280503.

26. Grafton ST, Mazziotta JC, Pahl JJ, St George-Hyslop P, Haines JL, Gusella J et al. Serial changes of cerebral glucose metabolism and caudate size in persons at risk for Huntington's disease. Arch Neurol. 1992;49(11):1161-7.

27. Boecker H, Kuwert T, Langen KJ, Lange HW, Czech N, Ziemons K et al. SPECT with HMPAO compared to PET with FDG in Huntington disease. J Comput Assist Tomogr. 1994;18(4):542-8.

28. Hayden MR, Martin WR, Stoessl AJ, Clark C, Hollenberg S, Adam MJ et al. Positron emission tomography in the early diagnosis of Huntington's disease. Neurology. 1986;36(7):888-94. 29. Kuwert T, Lange HW, Langen KJ, Herzog H, Aulich A, Feinendegen LE. Cortical and subcortical glucose consumption measured by PET in patients with Huntington's disease. Brain. 1990;113 ( Pt 5):1405-23.

30. Lee SJ, Lee WY, Kim YK, An YS, Cho JW, Choi JY et al. Apparent relative hypermetabolism of selective brain areas in Huntington disease and importance of reference region for analysis. Clin Nucl Med. 2012;37(7):663-8. doi:10.1097/RLU.0b013e3182478bf2.

31. Martin WR, Clark C, Ammann W, Stoessl AJ, Shtybel W, Hayden MR. Cortical glucose metabolism in Huntington's disease. Neurology. 1992;42(1):223-9.

32. Powers WJ, Videen TO, Markham J, McGee-Minnich L, Antenor-Dorsey JV, Hershey T et al. Selective defect of in vivo glycolysis in early Huntington's disease striatum. Proc Natl Acad Sci U S A. 2007;104(8):2945-9. doi:10.1073/pnas.0609833104.

33. Young AB, Penney JB, Starosta-Rubinstein S, Markel DS, Berent S, Giordani B et al. PET scan investigations of Huntington's disease: cerebral metabolic correlates of neurological features and functional decline. Ann Neurol. 1986;20(3):296-303. doi:10.1002/ana.410200305.

34. Kuhl DE, Metter EJ, Riege WH. Patterns of local cerebral glucose utilization determined in Parkinson's disease by the [18F]fluorodeoxyglucose method. Ann Neurol. 1984;15(5):419-24. doi:10.1002/ana.410150504. 
35. Kuwert T, Lange HW, Boecker H, Titz H, Herzog H, Aulich A et al. Striatal glucose consumption in chorea-free subjects at risk of Huntington's disease. J Neurol. 1993;241(1):31-6. 36. Mazziotta JC, Phelps ME, Pahl JJ, Huang SC, Baxter LR, Riege WH et al. Reduced cerebral glucose metabolism in asymptomatic subjects at risk for Huntington's disease. N Engl J Med. 1987;316(7):357-62. doi:10.1056/NEJM198702123160701.

37. Otsuka M, Ichiya Y, Kuwabara Y, Hosokawa S, Sasaki M, Fukumura T et al. Cerebral glucose metabolism and striatal 18F-dopa uptake by PET in cases of chorea with or without dementia. J Neurol Sci. 1993;115(2):153-7.

38. Young AB, Penney JB, Starosta-Rubinstein S, Markel D, Berent S, Rothley J et al. Normal caudate glucose metabolism in persons at risk for Huntington's disease. Arch Neurol. 1987;44(3):254-7.

39. Kuwert T, Noth J, Scholz D, Schwarz M, Lange HW, Topper R et al. Comparison of somatosensory evoked potentials with striatal glucose consumption measured by positron emission tomography in the early diagnosis of Huntington's disease. Mov Disord. 1993;8(1):98-106. doi:10.1002/mds.870080118.

40. van Oostrom JC, Dekker M, Willemsen AT, de Jong BM, Roos RA, Leenders KL. Changes in striatal dopamine D2 receptor binding in pre-clinical Huntington's disease. Eur J Neurol. 2009;16(2):226-31. doi:10.1111/j.1468-1331.2008.02390.x.

41. Ciarmiello A, Giovacchini G, Orobello S, Bruselli L, Elifani F, Squitieri F. 18F-FDG PET uptake in the pre-Huntington disease caudate affects the time-to-onset independently of CAG expansion size. Eur J Nucl Med Mol Imaging. 2012;39(6):1030-6. doi:10.1007/s00259-012-2114-z. 42. Feigin A, Tang C, Ma Y, Mattis P, Zgaljardic D, Guttman M et al. Thalamic metabolism and symptom onset in preclinical Huntington's disease. Brain. 2007;130(Pt 11):2858-67. doi:10.1093/brain/awm217.

43. Herben-Dekker M, van Oostrom JC, Roos RA, Jurgens CK, Witjes-Ane MN, Kremer HP et al. Striatal metabolism and psychomotor speed as predictors of motor onset in Huntington's disease. J Neurol. 2014;261(7):1387-97. doi:10.1007/s00415-014-7350-7.

44. Tang CC, Feigin A, Ma Y, Habeck C, Paulsen JS, Leenders KL et al. Metabolic network as a progression biomarker of premanifest Huntington's disease. J Clin Invest. 2013;123(9):4076-88. doi:10.1172/JCI69411.

45. Antonini A, Leenders KL, Spiegel R, Meier D, Vontobel P, Weigell-Weber M et al. Striatal glucose metabolism and dopamine D2 receptor binding in asymptomatic gene carriers and patients with Huntington's disease. Brain. 1996;119 ( Pt 6):2085-95. 
46. Ciarmiello A, Cannella M, Lastoria S, Simonelli M, Frati L, Rubinsztein DC et al. Brain whitematter volume loss and glucose hypometabolism precede the clinical symptoms of Huntington's disease. J Nucl Med. 2006;47(2):215-22.

47. Feigin A, Leenders KL, Moeller JR, Missimer J, Kuenig G, Spetsieris P et al. Metabolic network abnormalities in early Huntington's disease: an [(18)F]FDG PET study. J Nucl Med. 2001;42(11):1591-5.

48. van Oostrom JC, Maguire RP, Verschuuren-Bemelmans CC, Veenma-van der Duin L, Pruim J, Roos RA et al. Striatal dopamine D2 receptors, metabolism, and volume in preclinical Huntington disease. Neurology. 2005;65(6):941-3. doi:10.1212/01.wnl.0000176071.08694.cc.

49. Allain P, Gaura V, Fasotti L, Chauvire V, Prundean A, Sherer-Gagou C et al. The neural substrates of script knowledge deficits as revealed by a PET study in Huntington's disease. Neuropsychologia. 2011;49(9):2673-84. doi:10.1016/j.neuropsychologia.2011.05.015.

50. Berent S, Giordani B, Lehtinen S, Markel D, Penney JB, Buchtel HA et al. Positron emission tomographic scan investigations of Huntington's disease: cerebral metabolic correlates of cognitive function. Ann Neurol. 1988;23(6):541-6. doi:10.1002/ana.410230603.

51. Pagani M, Oberg J, De Carli F, Calvo A, Moglia C, Canosa A et al. Metabolic spatial connectivity in amyotrophic lateral sclerosis as revealed by independent component analysis. Hum Brain Mapp. 2016;37(3):942-53. doi:10.1002/hbm.23078.

52. Van Weehaeghe D, Ceccarini J, Delva A, Robberecht W, Van Damme P, Van Laere K. Prospective Validation of 18F-FDG Brain PET Discriminant Analysis Methods in the Diagnosis of Amyotrophic Lateral Sclerosis. J Nucl Med. 2016;57(8):1238-43. doi:10.2967/jnumed.115.166272. 53. Strong MJ, Abrahams S, Goldstein LH, Woolley S, McLaughlin P, Snowden J et al. Amyotrophic lateral sclerosis - frontotemporal spectrum disorder (ALS-FTSD): Revised diagnostic criteria. Amyotroph Lateral Scler Frontotemporal Degener. 2017;18(3-4):153-74. doi:10.1080/21678421.2016.1267768.

54. Chio A, Ilardi A, Cammarosano S, Moglia C, Montuschi A, Calvo A. Neurobehavioral dysfunction in ALS has a negative effect on outcome and use of PEG and NIV. Neurology. 2012;78(14):1085-9. doi:10.1212/WNL.0b013e31824e8f53.

55. Rascovsky K, Hodges JR, Knopman D, Mendez MF, Kramer JH, Neuhaus J et al. Sensitivity of revised diagnostic criteria for the behavioural variant of frontotemporal dementia. Brain. 2011;134(Pt 9):2456-77. doi:awr179 [pii] 10.1093/brain/awr179.

56. Lopez-Mora DA, Camacho V, Perez-Perez J, Martinez-Horta S, Fernandez A, Sampedro F et al. Striatal hypometabolism in premanifest and manifest Huntington's disease patients. Eur J Nucl Med Mol Imaging. 2016;43(12):2183-9. doi:10.1007/s00259-016-3445-y. 
57. Moher D, Liberati A, Tetzlaff J, Altman DG. Preferred reporting items for systematic reviews and meta-analyses: the PRISMA statement. J Clin Epidemiol. 2009;62(10):1006-12. doi:10.1016/j.jclinepi.2009.06.005. 